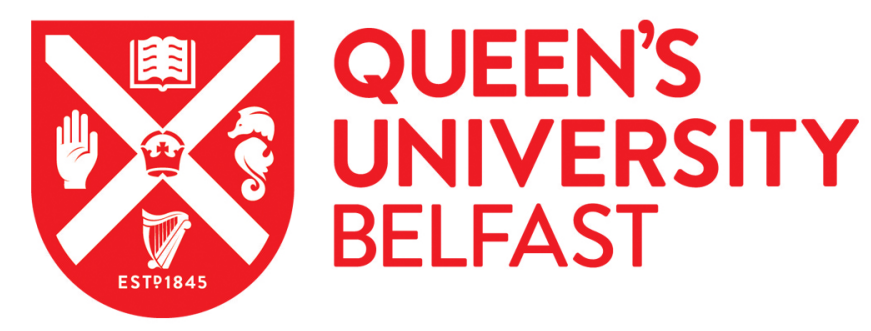

\title{
Collaborative cost-cutting: productive efficiency as an interdependency between public organizations
}

Elston, T., MacCarthaigh, M., \& Verhoest, K. (2018). Collaborative cost-cutting: productive efficiency as an interdependency between public organizations. Public Management Review, 20(12), 1815-1835. https://doi.org/10.1080/14719037.2018.1438498

Published in:

Public Management Review

Document Version:

Peer reviewed version

Queen's University Belfast - Research Portal:

Link to publication record in Queen's University Belfast Research Portal

Publisher rights

Copyright 2018 Taylor \& Francis. This work is made available online in accordance with the publisher's policies. Please refer to any applicable terms of use of the publisher.

\section{General rights}

Copyright for the publications made accessible via the Queen's University Belfast Research Portal is retained by the author(s) and / or other copyright owners and it is a condition of accessing these publications that users recognise and abide by the legal requirements associated with these rights.

Take down policy

The Research Portal is Queen's institutional repository that provides access to Queen's research output. Every effort has been made to ensure that content in the Research Portal does not infringe any person's rights, or applicable UK laws. If you discover content in the Research Portal that you believe breaches copyright or violates any law, please contact openaccess@qub.ac.uk. 


\title{
Collaborative Cost Cutting: Productive Efficiency as an Interdependency between Public Organizations
}

Article accepted January 2018 and forthcoming in Public Management Review

Dr Thomas Elston, University of Oxford

Dr Muiris MacCarthaigh, Queens University Belfast

Prof Dr Koen Verhoest, University of Antwerp

\begin{abstract}
Collaboration between public sector organizations is typically understood as a response to complexity. Agencies collaborate in order to address complex, crosscutting policy needs that cannot be met individually. However, when organizational size is a constraining factor in public service efficiency, collaboration can also reduce costs by capturing scale economies unavailable to organizations of sub-optimal size. Using organization theory, the article conceptualizes these two different triggers for public sector collaboration, and builds a framework for tracing their wider impact upon the formation, operation and outcome of inter-agency partnerships. The framework is illustrated, and its implications for future research explored.
\end{abstract}

\section{Keywords}

Efficiency; organization theory; shared services

\section{Funding}

Part of this research was funded by the Leverhulme Trust, Grant No. ECF/2014-069 


\section{Collaborative Cost Cutting: Productive Efficiency as an Interdependency between Public Organizations}

There is growing interest, among scholars and practitioners alike, in the role that inter-organizational collaboration can play in reducing the cost of delivering public services to citizens (Chen \& Thurmaier, 2008; Dollery et al., 2012; Bel \& Warner, 2015; Raudla \& Tavares, 2018; Allers \& de Greef, forthcoming). In the case of local government, the idea of local authorities jointly providing services across separate jurisdictions is not new, having often been cited as an alternative to council amalgamations in long-running discussions about efficiency and optimal scale in municipal service delivery (Ostrom et al., 1961; Ostrom, 1974). Such "inter-local" arrangements have come of age since the global financial crisis, with examples including shared residential waste collection (Zafra-Gómez et al., 2013; Bel et al., 2014), police departments (Zeemering, forthcoming), fire and rescue services (Blåka, forthcoming), tax collection (Niaounakis \& Blank, 2017), and back-office functions (Elston \& Dixon, 2017). Similarly, in national government, recent budgetary constraints have exposed the negative financial implications of operating central public services through autonomous departments and agencies. Collaborative solutions, involving personnel sharing and joint provision of common activities like public procurement, information technology and professional expertise, are often being implemented in place of, or alongside, mergers to create larger ministries (Department of Public Expenditure and Reform, 2011; Cabinet Office, 2012; Department of Finance, 2015; Office of Management and Budget, 2016).

Although recognizably instances of public sector collaboration, these efficiency-inspired inter-organizational arrangements do not conform well with the familiar understanding of "collaborative public management" as a response to policy 
complexity. Typically, public agencies are thought to collaborate in order to address complex and cross-cutting policy needs that cannot be met individually (Gray, 1985; Challis et al., 1988; Peters, 2015). And yet in the aforementioned examples, it is the search for cost savings, not the demand for joined-up policies, that provokes the partnership. It remains unclear whether this distinction is subtle and of little consequence, or whether it carries great practical or theoretical relevance. To date, most studies of collaborative cost cutting have been quantitative evaluations of financial performance. While hugely valuable, questions have gone unasked about how the complexity and efficiency triggers for collaboration relate to one another, and what significance - if any - these differing antecedents have for the formation, operation and outcome of partnerships. Transaction cost economics, a popular framework in large-N evaluations, provides limited guidance on this matter, and nor is the mainstream collaborative public management literature geared towards understanding "how collaboration might differ depending on the nature of the issue or task to be dealt with,” as Bryson et al. $(2015, \mathrm{p} .650)$ recently observed. Yet questions about the distinctiveness of collaborative cost-cutting are important if we are to understand the current direction of travel in public service delivery, advance collaboration research, and provide sound policy advice.

Consequently, in this article, we turn to organization theory to conceptualize the similarities and differences between the complexity and efficiency motivations for public sector collaboration - and suggest some possible consequences for the unfolding of partnerships. Overall, our argument is that the two forms are alike in so far as each addresses an interdependency arising between two or more organizations; but are dissimilar in the kind of interdependency being addressed. Complexity-driven collaboration confronts task interdependencies, while the efficiency type focuses on 
interdependencies of scale. These distinct antecedents may impact significantly upon key aspects of the collaboration, including partner selection, institutional collective action, mode of leadership and performance evaluation. In the confines of one article we cannot enumerate and test all the possible implications, but we do provide primafacie grounds for exploring the issue further.

The article is structured as follows. The first section explores the mechanisms by which inter-organizational collaboration might cut the cost of public service delivery. The second builds a model of collaboration that connects the complexity and efficiency types and provides a basis for comparing the impact of alternative motivations upon partnership formation, structure and outcomes. The third section illustrates the model with a recent multi-agency "shared service" reform in England. Finally, the fourth section highlights areas for future research.

\section{Collaboration and Productive Efficiency of Public Services}

Efficiency is a favourite concept in public service reform. Andrews and Entwistle (2013) identify four distinct uses of the term in such debates. Our interest is in productive efficiency, which describes the ratio of inputs (staff, raw materials) to outputs (products, services) in an organization. This can be enhanced in several ways, including by maximizing outputs while holding inputs constant, reducing inputs while preserving outputs, increasing inputs but increasing outputs proportionally more, or decreasing inputs while decreasing outputs proportionately less (Pollitt \& Bouckaert, 2011, pp.140-143). Productive efficiency is usefully conceived in relative rather than absolute terms. As Herbert Simon (1997, p.256) wrote, "The efficiency of a behaviour is the ratio of results obtainable from that behaviour [compared to] the maximum of results obtainable from the behaviours which are alternative" (emphasis added). In other words, inefficiency arises when there exists a different method of 
producing services that would deliver better input-output productivity. This distinguishes efficiency from "economy," which refers more simply to an absolute reduction of inputs (Pollitt \& Bouckaert, 2011, pp.135-136).

Among the alternative methods available to public managers looking to improve public service efficiency are many "internal" strategies that agencies can implement without resorting to collaboration. However, productive efficiency is often significantly contingent upon the size of an organization's output, and it is here that collaborative solutions may be required.

Economies of scale and scope occur when there are cost advantages to larger organizational output (Besanko et al., 2003). For economies of scale, average unit costs decline as output increases, generally because fixed costs are diluted and higher workloads allow staff specialization. Often, the relationship is non-linear, with returns to scale gradually slowing (producing an L-shaped curve) or turning negative (a U-shape) - for example, if disproportionate bureaucratic growth accompanies increased output. Economies of scope occur when production costs fall as the variety of goods and services produced using the same methods increases; for instance, if knowledge developed for one service is relevant to another. To some extent, public organizations can pursue both scale and scope economies internally, by redesigning processes or restructuring departments. However, once these efforts are exhausted, an external "growth pathway" is required (Bovaird, 2014).

Policymakers and researchers often discuss the optimal scale at which to deliver local public services, and the growth opportunities for achieving that optimum (Lago-Peñas \& Martinez-Vazquez, 2013). In a seminal article, Ostrom et al (1961, p.853) list factors determining municipal size as: "[ease of] control, efficiency, political representation and self-determination." Because productive efficiency is 
only one consideration, and is "sometimes in conflict" with others, local authorities often deliver services at suboptimal scale from a cost point of view. Moreover, even if productive efficiency were made the overriding consideration, public agencies are frequently multipurpose, performing diverse tasks with varying cost functions (Oakerson, 1992). Hence, a degree of inefficiency is still likely if one organization provides multiple services.

These problems are not confined to local government. Questions about organizational size, degree of specialization, and ease of public service control and accountability confront central policymakers too (Hood et al., 1985). Re-structuring the machinery of government to achieve larger or smaller output is a favourite lever of reform, as the international wave of bureaucratic disaggregation and decentralization during the "new public management" era (subsequently reversed in many cases) illustrates (Verhoest et al., 2011).

Whether at the local or national levels, if amalgamating public service agencies in pursuit of scale and scope economies is not possible or desirable, interagency collaboration in carefully selected activities is a promising alternative for improving productive efficiency (Thurmaier \& Wood, 2004; Dollery, et al., 2012; Bel \& Warner, 2015). As Andrews and Entwistle (2013, p.38) explain: "In theory, economies of scale can be garnered just as effectively where one or more providers are required to produce outputs jointly, as when those providers are merged to increase the overall scale of the operation." By such collaboration, the hope is to maintain organizational boundaries that match control or accountability preferences, while up-scaling output to approach the optimum for the activity in question.

This use of collaboration to realize size-contingent economies otherwise unavailable to autonomous public agencies is quite distinct to the task-complexity 
explanation that currently dominates the collaborative public management literature. Admittedly, in practice, motives for collaboration are often multiple and blurred.

Collaboration may enable increased investment in higher-capability staff or equipment with which to tackle difficult policy problems, resulting in more effective organizations owing to more efficient use of resources. Nonetheless, for analytic purposes, it is useful to distinguish efficiency-driven collaboration from both the familiar task-complexity type, and from the alternative in-house cost-cutting solutions available to public managers. To do so, we adapt Agranoff and McGuire's (2003) widely-used description of collaborative public management to define a distinct class of partnership arrangements labelled "collaborative efficiency measures," thus:

Collaborative efficiency measures are multi-organizational arrangements designed to achieve levels of productive efficiency that cannot be achieved, or achieved easily, by single organizations.

\section{Collaboration: The View from Organization Theory}

Having distinguished between the complexity and efficiency triggers for public sector collaboration, we turn now to how they are related, conceptually, and whether the distinction has significant consequences for how partnerships unfold. Theoretically, the underlying trigger for all forms of collaboration is interdependence (Gray, 1985; Alexander, 1995). According to Pfeffer and Salancik (1978, p.40), "Interdependence exists whenever one actor does not entirely control all of the conditions necessary for the achievement of an action or for obtaining the outcomes desired from the action." Interdependence is implicit in the economic theories of inter-organizational exchange that increasingly inform research on collaborative public management (Carr \& Hawkins, 2013; Feiock, 2013). But a rich and recently overlooked literature can also be found in organization theory, with empirical cases drawn from both public and 
private sectors. This provides a nuanced, multidimensional foundation for analysing relations between public organizations, and is the basis of our analytic framework. It posits that interdependencies are not only a cause of collaboration, but also an (unintended) consequence; that interdependencies occur in multiple aspects of organizational design, including task and scale; that interdependencies vary in strength, intricacy, direction and ease of recognition; and that interdependencies can be managed by a variety of governance mechanisms. Figure 1 summarizes the framework. The central logic is that when there exists an interdependence between two or more agencies, in the form of a mutually-desired outcome that is difficult to achieve autonomously, a collaboration might be formed, controlled by a variety of

governance mechanisms. As this unfolds and the initial interdependency is tackled, partners begin to experience new interdependencies caused by constraints that joint working imposes on each individual member. These new connections also require handling through the governance mechanism, and may reduce the net benefit of collaboration.

\section{>>>INSERT FIGURE 1 HERE $<<<$}

\section{Ex-ante and Ex-post Interdependence}

Organization theory views interdependence as both a cause and a consequence of collaboration - a distinction we label as "ex-ante" and "ex-post" interdependence. In terms of antecedents, Oliver (1990) suggests six key reasons for collaboration between organizations: to comply with mandates from higher authorities ("necessity"); to manage a critical relationship ("asymmetry"); to pursue "mutually beneficial goals or interests" ("reciprocity"); to reduce internal costs ("efficiency"); to increase the predictability of the external environment ("stability"); and to appear 
acceptable in the eyes of key stakeholders ("legitimacy"). Five of these six reasons assume a state of interdependence between collaborators. If there is problematic "asymmetry" or potential for "reciprocity" between organizations, or if "efficiency," "stability," and "legitimacy" all require collaboration, then - logically - these desirables must be beyond the direct control of management - the crux of Pfeffer and Salancik's definition (above). Organizations thus enter into partnerships "to access capabilities and resources that are essential to pursue their goals but that are at least in part under the control of other organizations in their environment" (Gulati \& Gargiulo, 1999, p.1443).

This view of interdependence as triggering collaboration is widespread. For Alexander (1995, p.271), it is the "critical stimulus," while Gray (1985, p.921) suggests that inter-organizational relations "make no sense" without "some fundamental interdependence." But interdependence also results from collaboration “ex post” (see Figure 1). As Aiken and Hage (1968, pp.913-914, 917) argue: "The greater the number of joint programs [between organizations], the more organizational decision-making is constrained through obligations, commitments, or contracts with other organizations" (emphasis added). Because of these constraints, actors "become netted together in a web of interdependencies." Such ex-post interdependencies take several forms. One is a loss of autonomy for each member of the partnership, particularly in decision-making and work scheduling. This in turn can increase the bargaining time required to agree collective decisions - something Hood (1976, p.89) refers to as the problem of "multi-organization sub-optimization." Ex-post interdependence also means that organizational performance is subject to the actions, mistakes and opportunism of others in the partnership. What was previously self-determined is now contingent on others' behaviour. 
The potential for collaboration to induce ex-post interdependence requires managers to weigh the benefits of resolving ex-ante interdependencies against the problem of creating new ones. As Chisholm (1989, p.58) explains, "when mechanisms for coordination [between organizations] are overly complex relative to the extent and type of [ex-ante] interdependence, the causal flow may be reversed, with the mechanisms themselves creating higher levels of [ex-post] interdependence, linking organizations more tightly than before." In international relations, this is described as "self-reinforcing interdependence" (Hale et al., 2013). Ultimately, if expost interdependencies become more damaging than the ex-ante interdependencies that are being resolved, the decision to collaborate may have been incorrect.

\section{Task and Scale Interdependencies}

Ex-ante and ex-post interdependence occur in sequence, as indicated on the vertical axis in Figure 1. But, substantively, there are also different types of interdependence, found on the horizontal plane. These help to distinguish the complexity- and efficiency-driven forms of public-sector collaboration.

Task (or "workflow") interdependence describes how employees, teams, departments and whole organizations relate to one another in the process of providing goods and services that ultimately deliver an organization's goals (Thompson, 1967; March \& Simon, 1993). If one element is missing or underperforms, the effectiveness of the whole undertaking is jeopardised. Such task interdependence is the prompt for mainstream, complexity-driven collaboration in the public sector. Specialist agencies, unable to achieve cross-cutting policy goals individually, must coordinate their efforts (Peters, 2015). They are interdependent because, without each other's coordinated input, the desired policy outcome cannot be achieved satisfactorily. 
Scale interdependencies, by contrast, concern productive efficiency, rather than effectiveness. Given the relationship between output and cost, described above, they arise when different units of organization depend upon one another to generate sufficient volume of work for efficient utilization of resources (Mintzberg, 1979, pp.115-124) - for instance, sharing x-ray equipment or laboratory expertise between different hospital departments. Scale interdependencies thus describe two or more parties that are mutually reliant on one another's demand for a particular function so that efficient levels of output are reached, making the function affordable to all.

It is these ex-ante scale interdependencies, not interdependencies of task, that trigger efficiency-driven collaboration. As discussed, small public agencies can suffer from inefficiencies if they are unable to deliver services at the optimum point on the cost curve. But if there is overlap in the technologies operated in separate organizations, economies of scale and scope can be realized through joint provision, which increases output and so reduces that inefficiency. Collaborators depend upon one another to achieve this up-scaling, which is not possible individually; and yet may become subject to a series of ex-post constraints in return.

\section{Strength, Intricacy, Direction and Recognition}

Besides the temporal distinction between ex-ante and ex-post interdependence, and the substantive contrast of task and scale interdependence, organization theory identifies a number of other variables relevant to comparing the formation, operation and outcome of public sector partnerships. These are summarized as bullet points in Figure 1. Note their applicability to interdependencies in both the ex-ante and ex-post positions.

Strength. Firstly, interdependencies vary in strength, measured by the number of interconnected activities, the number of actors involved, or the opportunity 
cost of acting autonomously (on the latter, see Baldwin, 1980). Stronger interdependencies require greater coordination. Thus, Keast et al. (2007) find different "intensities" of inter-organizational relation corresponding to different degrees of interdependence between public organizations, ranging from partial "cooperation," through more active "coordination," to intensive "collaboration."

Intricacy. The intricacy of an interdependence also affects coordination method. March and Simon (1993, p.180) focus on its predictability. If "contingencies ... cannot be predicted perfectly in advance," there must be real-time communication and mutual adjustment between interdependent actors, rather than simpler (and cheaper) coordination through pre-planned rules and work schedules. Similarly, Thompson (1967) categorizes interdependencies as "pooled," "sequential," or "reciprocal." Pooled is simplest, describing autonomous contributions to the workflow. Sequential demands greater coordination between workers, with a chain of output-input relations across the organization. Reciprocal interdependence is most intricate, occurring when there is a two-way, dynamic relationship between units. This level of intricacy creates high coordination costs.

Direction. A third variable is whether goals are aligned or conflicting between interdependent actors. As Tjosvold (1986, p.524) explains: "In positive interdependence ... one's movement toward one's goals facilitates others' goals. ... In negative interdependence ... one's goal movement interferes with and makes it less likely that others will reach their goals." Public organizations competing for limited funds are in negative interdependence, since outcomes are mutually contingent but benefits distributed zero-sum. Conversely, agencies under pressure to achieve a cross-cutting policy target, for which they are both rewarded, experience positive interdependence. Defection problems are a specific type of negative interdependence 
noted in the economic literature, describing one party's reneging on their agreed commitments to the detriment of the others (Feiock, 2013). Since defection occurs after collaboration has begun, it is also an example of ex-post interdependence.

Recognition. Lastly, there is an epistemological question about cognition and social construction. Often there is a "lack of perfect correspondence between 'objective' and 'perceived' interdependence" (Deutsch, 1949, p.138), meaning that organizational actors overlook crucial interdependencies, exaggerate them, or even invent them. Strength, intricacy and direction of interdependence might also be interpreted differently by different (groups of) actors (Litwak \& Rothman, 1970; Tjosvold, 1986). Given the aforementioned need to carefully weigh ex-ante and expost interdependencies to ensure a net gain from collaboration, such contestable and imperfect information is problematic. Indeed, Litwak and Rothman (1970, pp.150151) find that, "[often] there is a stress on interdependence where in fact none exists. ... Agency personnel meet with each other and attempt to coordinate their activities when ... there is not sufficient interdependence to warrant it."

\section{Governing interdependent organizations}

How can policymakers coordinate public agencies to deliver valued outcomes that are subject to interdependencies? It is here that "governance," in the sense of giving direction to a social system, provides an answer. Following the classic distinction between hierarchy, market and networks (Thompson et al., 1991; Bouckaert et al., 2010), three ideal-type methods of inter-agency governance can be envisaged. These apply, firstly, to the identification of the ex-ante interdependence and the decision to collaborate. We refer to these initial processes as "reform governance". Secondly, the on-going relations between partners, including decisions about how to manage 
emerging "ex-post" interdependencies, are termed "operational governance." These two stages are labeled in boxes in Figure 1, along with the feedback loop.

Hierarchical governance. In the hierarchical mode, actors interact on the basis of dominance and authority, achieved through administrative orders, rules and planning. Collaboration begins when higher authorities recognize potential interdependencies between subordinate agencies and instigate top-down reforms to correct them (reform governance). Thereafter, control of the collaboration rests at a higher administrative level or with a "lead" organization, rather than individual participants co-deciding how interdependencies are to be addressed (operational governance). Thus, service specifications, budgeting, resource allocation and the resolution of grievances (including problems of ex-post and negative interdependence, indicated in Figure 1 with the feedback loop) are largely removed from direct control of individual organizations.

Market-based governance. Market governance is based on competition, bargaining and exchange between actors. The price mechanism, incentives and selfinterest coordinate actors through the "invisible hand." Thus, reform ideas are "sold" to governments by management consultants, private sector providers and public agencies offering paid-for services, who generate efficiencies not only from upscaling, but also from competitive pressures and entrepreneurialism. Operationally, coordination is achieved by different providers "reading" the market and developing appropriate solutions to sell to informed and mobile "clients." This mode of governance relies on detailed contracts and performance-dependent funding.

Network governance. Finally, governance through networks involves voluntary cooperation between actors. This rests on common knowledge, values and strategies between partners. Networked reform governance means self-recognition of 
potential synergies within the group, and voluntary determination of a collaborative response. Networked operational governance means partner organizations cogoverning the collaboration, designing services and monitoring performance together, and resolving any ex-post interdependencies through dialogue and compromise.

\section{Collaborative Efficiency Measures in Practice}

Having distinguished the complexity and efficiency motives for collaboration in the public sector, and constructed a framework for studying collaborative efficiency arrangements, this section illustrates how that abstract model can be applied to a reallife situation. The aim is to clarify the framework, summarized in Figure 1, by demonstrating the concepts in action. Our example is an arrangement for joint delivery of back-office support services by three independent public agencies in the English county of Hampshire. These "shared service centres" are increasingly popular in local, regional and national government in many countries (Paagman et al., 2015; Elston \& MacCarthaigh, 2016).

\section{Background: Creating a Shared Service Centre in Hampshire ${ }^{1}$}

Hampshire is a rural county in the south of England, with 1.32 million residents. Like the rest of the UK, its public services faced severe spending cuts after 2010, when central government began a major program of retrenchment (Hastings et al., 2015). In 2011, the leaders of three of the county's largest public service agencies, the County Council, the Police, and the Fire and Rescue Service, pledged in a joint "Statement of Commitment" to work together to tackle some of the funding shortfall by developing a county-wide shared service centre. The aim was back-office

\footnotetext{
${ }^{1}$ In compiling this illustration, we analysed internal partnership documentation from the period 20112015, including: the Strategic Case, Business Case, nine-month report to Hampshire Council Audit Committee; six-month and one-year reports to Hampshire Fire Service; and Note to Cabinet (Oxfordshire County Council). Unless otherwise stated, all quotations in this section are sourced from these documents.
} 
savings of 20 per cent, as well as increased operational resilience for smaller partners, digitization of manual administrative processes, and significant upgrades to information technology.

This decision came at a time of general enthusiasm for administrative efficiencies in the UK, given the need to limit cuts to frontline services. A number of consultancy reports, management books and government-commissioned analyses had advocated shared service centres for several years (Gershon, 2004; Accenture, 2005; Tomkinson, 2007). The Cabinet Office was implementing the model in central government (Cabinet Office, 2012; National Audit Office, 2016). And, in published advice to council managers, the Department for Communities and Local Government (2012) ranked shared services first among fifty ways to make "sensible savings in local government." Uptake of this approach was widespread: by 2016, three-quarters of local authorities in England participated in one or more shared service, although generally across rather than within council areas (Elston \& Dixon, 2017).

In Hampshire, the council, police and fire services had a track record of collaborating "to meet shared visions, aims and objectives in a cross-cutting and joined-up manner." One example is Hampshire County Strategic Group for Crime and Disorder. The council also sold a number of back-office services to other, smaller public agencies. The working relationships and collaborative ethos fostered by these existing partnerships were critical to instigating the new back-office consolidation project, which was branded "H3." This would create: (i) a single administrative processing entity for the three partners, with responsibility for transactions like payroll and payment of suppliers; (ii) a series of centralized functional departments to undertake more complex, advisory work; and (iii) a single 
leadership team, with, for instance, one Head of HR serving the council, police and fire service simultaneously.

During project design and implementation, the council (as the largest partner) hosted the $\mathrm{H} 3$ team, with secondees from police and fire services. External consultants were commissioned to provide support. The "three chiefs" - that is, the council's Chief Executive, the Chief Constable, and the Chief Fire Officer - retained a close interest throughout, and the partnership's legal structure was selected to “[ensure] co-ownership and control with a genuine partnership ethos." Upfront investment and expected annual savings were distributed between partners according to a pre-agreed ratio $(73 \%$, council; $22 \%$, police; $5 \%$, fire). Central-government funding also assisted with start-up costs.

From the outset, the intention was for other agencies within and beyond the county boundary to gradually join the three "founding partners," further increasing the economies generated. In 2015, Oxfordshire County Council became the first to do so, contributing additional work volumes and personnel. Oxfordshire used the same management consultants to oversee the transfer. Other "operational partners" are currently being sought.

Box 1 summarises main achievements of the $\mathrm{H} 3$ collaboration during the initial nine months of operations.

\section{Box 1. H3 Achievements in Nine Months from April 2014}

- Three founding partners fully "on-boarded," involving the largest change to council administrative processes and ICT in a decade

- Services sold to 500 schools in Hampshire

- Oxfordshire County Council slated to join as new "operational partner" in 2015 (bringing 200 additional schools)

- 250 staff working in the administrative processing centre, drawn from three founding partners and working in single location 
- Over 55,000 individual users supported by the processing centre, which received 91,000 customer contacts via telephone and online

- 94 per cent of council staff registered for online employee "self-service," compared with 55 per cent of fire service staff

- 434,113 salary payments made through payroll

- $\quad 107,600$ leave requests, 10,700 sickness absences, 59,947 employee expense claims, and 2,665 recruitment requests processed

- 433,583 invoices paid ( 85 per cent on time) to over 10,000 suppliers

(Source: Project documentation)

\section{Analysing "H3"}

Below, we consider Hampshire's cost-cutting reforms using the analytic framework. The analysis is structured around the key headings in Figure 1.

1. Ex-ante interdependence. In general, the shared service centre model assumes that all organizations, whatever their primary purpose, have certain basic administrative needs in common with one another. The cost curve for these functions is believed to mean that in-house provision is inefficient. Inter-agency collaboration should overcome that inefficiency (Elston \& MacCarthaigh, 2016).

This general logic certainly reflects thinking in Hampshire at the time H3 was established. Under significant budgetary pressure, and encouraged by prior joint working to resolve task interdependencies in policy areas like crime prevention, the partners undertook high-level analysis in 2011 that revealed numerous "organizational fits" between them, including "back office functions [that] provide a similar type and level of support." This duplication presented a "basket of opportunity" for rationalization. Collaborative provision would bring "an increase in economies of scale, a greater critical mass" in administrative functions, and enable "attraction and retention of core capacity, skills and resources." The "three chiefs" considered these size-contingent benefits to be unavailable to each organization individually. As they wrote in the Business Case: "What we can achieve collectively will be far greater than 
what we can achieve on our own." Thus, H3 was motivated by positive scale interdependencies between partners. Significantly, nothing had occurred organizationally to create these ex-ante interdependencies in 2011. In fact, administrative duplication is simply a corollary of decentralized arrangements for public service delivery - in Hampshire as elsewhere. Yet the national salience of the shared services model at this time made for an environment in which potential scale interdependencies were brought to the fore and easily recognized by officials.

One method of gauging the strength of ex-ante interdependence between council, fire and police is to consider the opportunity costs of not collaborating to resolve the interdependency (Baldwin, 1980). H3 emerged at a time when significant cost-saving programmes were already underway internally in the founding partners. The H3 Business Case took those savings as given, and then estimated the further efficiencies - approximately 20 per cent - "that could not be achieved without working jointly." These benefits of up-scaling would be an opportunity cost if partners chose to continuing acting autonomously. Similarly, for Oxfordshire County Council, joining H3 in 2015 allowed it to vacate a building leased for administrative operations, cancel a software license for its enterprise resource management platform, and make a series of staff redundancies and redeployments. Again, these savings were not thought possible without collaboration. Nonetheless, for all collaborators, initial assessment of interdependence was subject to bounded rationality and subsequent revision. In particular, their precise level of administrative similarity was unknown at the outset, as was the ability of these complex, multi-department and multi-site organizations to move into greater alignment. These uncertainties led to an evolving perception of the strength and intricacy of ex-ante interdependence as the reform progressed, as described below. 
2. Reform governance. Once the potential for joint back-office

administration between police, fire and county council was established in broad terms, the decision to proceed was taken locally by the governing bodies of the organizations, advised by the three chiefs. There was no top-down instruction from central government. The project thus developed with a network style of reform governance, involving “joint direction, governance and control of resources." Yet, from the beginning, the intention was for $\mathrm{H} 3$ to provide both "shared and sold corporate services," attracting new customers to enlarge the economies of scale and scope. For instance, if $\mathrm{H} 3$ could sell to another police or fire organization, this would expand the enterprise considerably, capitalizing on investments already made in understanding the administrative needs of these particular services. To do so, $\mathrm{H} 3$ needed to position itself "alongside the best performing and lowest cost operations in the private sector." This was a key motivation for appointing external consultants. It also suggests that, over time, reform governance will shift towards a market-like approach, with managers actively approaching new customers, highlighting areas in which scale interdependencies can be exploited, and competing on cost and quality with external public and private providers. This style of shared service centre is already underway in other contexts, including US federal government (see Partnership for Public Service \& Deloitte, 2015).

3. Ex-post interdependence. According to the analytic framework, partnership formation brings the possibility of new, "ex-post" interdependencies between members. These are constraints placed on organizations as a result of the collaboration, including reduced autonomy, increased bargaining time for group decisions, and vulnerability to the actions, mistakes and opportunism of other parties. 
The overall effect may be self-reinforcing, where ever-greater pursuit of ex-ante interdependencies leads to ever-greater ex-post connectivity.

Beginning with loss of autonomy, from the outset it was recognized that significant, co-ordinated change would be required to bring the $\mathrm{H} 3$ organizations into alignment administratively - although the three chiefs stressed that their agencies would retain distinct public-facing identities. The challenges of standardization became more apparent as the project developed. Administrative activities previously performed at suboptimal scale but under direct control of managers in each organization would now be undertaken at more efficient scale but at arm's-length and in standardized fashion. This would make task completion for day-to-day activities (ostensibly) cheaper but multi-step and multi-party, involving any combination of: users, the administrative processing centre, centralized functional teams, and/or $\mathrm{H} 3$ project managers. Thus, while H3 was motivated by scale interdependencies in the beginning, the effect was to produce new task or "workflow" interdependencies between separate teams, departments and organizations.

The significance of these ex-post task interdependencies varied, as the schedule for implementing $\mathrm{H} 3$ reveals. Heavily professionalized services, like strategic finance and occupational health, were transitioned early into H3. Little effort was required to arrive at a single service suitable to all partners; and, once consolidated, each organization could use the new service with relative ease. Conversely, creation of the single administrative processing center involved "a more complex reconfiguration of ICT infrastructure," as well as considerable process mapping and standardization between partners. This was more complicated to arrange, and the coordination burden was significantly higher. Thus, it seems that the intricacy of the connections being formed ex-post - their straightforwardness and 
predictability - influenced the scheduling of the reform, with those activities requiring greatest coordination taking longest to align.

As for increased decision and bargaining time, aligning administrative processes across organizations required extensive deliberation and information exchange. Consequently, as described below under operational governance, multiple consultative and decision forums were established which, prior to the collaboration, were unnecessary. Agencies also recognized their new vulnerability to each other's actions during this process. Each founding partner had a track record of "consistently strong performance," reflected in national league tables, which reassured the others about the intent and ability to make the collaboration a success. Nonetheless, the legal vehicle chosen for the partnership contained "binding and enforceable contractual arrangements," allowing for means of redress if necessary. Moreover, as a latecomer to, and subordinate member of, $\mathrm{H} 3$, Oxfordshire foresaw risks in joining a partnership that operated on a "cost share basis" without enjoying equal say in its strategic direction. Contractual assurances were sought.

4. Operational governance and feedback. Finally within the analytic framework, "operational governance" refers to on-going management of the collaboration, including dealing with negative and ex-post interdependence between partners (labelled with a feedback loop in Figure 1).

The network style of H3's initial reform governance continued into the implementation phase, albeit with greater formalization. A Programme Delivery Board was formed, chaired by the Council Treasurer but comprising representatives from each partner and reporting to the three chiefs. Beneath this, separate workstreams focused on specific functional areas, like HR. Similarly, to manage Oxfordshire's transfer in 2015, there was “On-Boarding Project Board,” a project 
team, and eleven separate workstreams. As an operational partner, Oxfordshire joined H3's "operational forum," but also used financial and non-financial metrics for performance management, again indicating a more market-like governance regime.

To manage ex-post interdependencies emerging from the consolidations, the team combined elements of networked governance with the hierarchical authority granted by H3's senior backing. On the former, following one partner resisting an aspect of process automation, a workshop was scheduled for an "honest reassessment" of progress made and the damage being caused to the overall business case realization. The need for this review demonstrates the strength of the ex-post interdependence: everyone's finances were adversely affected by one partner's actions. Conversely, when an investigation into repeated late payment of invoices by the administrative processing centre actually blamed "a combination of poor user and supplier practice, who are not following agreed processes," the response was to "reiterate the correct procedures" to offending parties.

Both the automation and invoicing cases illustrate how ex-post connections can be negative in direction, even when the motivating ex-ante interdependence is positive. All partners want maximum up-scaling of administrative output to achieve the greatest efficiency possible; and yet, given the disruption involved in changing working methods and processes, each would prefer the others to adapt to their current way of working.

On rare occasions where the combination of networked and hierarchical governance failed to overcome the hurdles of inter-agency standardization and expost interdependence, there was reluctant adjustment of reform ambitions. After nine months of trying to alter processes in hundreds of schools in Hampshire, a new, "least-change" option was discussed, involving less automation and "in essence 
return[ing] ... to the previous operating model." This was acknowledged as reducing the benefits of collaboration, but was necessitated by implementation difficulties. Similarly, as Oxfordshire worked through the process of joining H3, it reduced the scope of the services to be transferred as it became apparent that overlap between parties was less than initially thought, and/or the cost of alignment too great.

These modifications return us to the earlier point about the evolving recognition of interdependence during $\mathrm{H} 3$ 's implementation. Economies of scale arise from delivering the same services in greater volume - not simply from performing dissimilar activities in one location. Consequently, the strength of exante interdependence motivating the back-office partnership is, in practice, conditioned by the degree of administrative alignment between partners and their willingness and/or ability to implement coordinated change. Both of these factors were uncertain at the outset.

\section{Reflections on the illustration}

We conclude this illustration with several observations.

First is that the orthodox explanation of public sector collaboration as a "rational response to the complex, untidy sprawl of social problems [that public organizations face]" (Challis, et al., 1988, p.2) is clearly inadequate to provide an account of H3. It was not the need for joined-up public policies that motivated the partnership, but the belief that suboptimal organizational size led to inefficient administrative functions. As such, Hampshire's reforms epitomize our definition of “collaborative efficiency measures.” Individual cost-cutting programmes were already underway in the three separate agencies, and yet it was the search for higherorder savings, beyond what could be achieved individually, that triggered the project. Improved productive efficiency was the motivating interdependency. 
Secondly, whereas most existing evaluations of collaborative cost cutting focus on major frontline public services delivered by decentralized local governments (Zafra-Gómez, et al., 2013; Bel, et al., 2014; Blåka, forthcoming), H3 demonstrates the logic's applicability to non-frontline services. Indeed, the assumption that organizations, no matter their primary function, have certain basic administrative needs in common expands the range of possible inter-agency partnerships considerably, including to the national level which has hitherto been overlooked in studies of collaborative cost-cutting. In the same vein, procurement cooperatives involve two or more agencies, at the central or local level, jointly buying goods and services from the market in order to achieve bulk-buy discounts and lower transaction costs compared with autonomous purchasing (Walker et al., 2013). The model developed in this paper helps explain such practices, regardless of their level of implementation.

\section{Discussion}

We return now to the question posed in the introduction. Does the complexityefficiency distinction in collaborative motivation have significant consequences for how public sector collaborations unfold? New empirical research is required to fully address this issue, but our framework provides a platform upon which to build.

In terms of partnership formation and sustainability, the distinction between task and scale interdependence has at least three implications. Firstly, while a degree of choice accompanies partner selection for most collaborations (Silva, 2017), greater latitude is possible when resolving scale interdependencies. Collaborators are drawn together not by prescribed externalities in a specific policy field or locale, but because of overlapping organizational technology. Many options were open to $\mathrm{H} 3$ collaborators looking to up-scale their generic administrative 
functions. The police and fire services could have approached their counterparts in neighbouring counties, while Hampshire and Oxfordshire County Councils could have joined with lower-tier councils in their respective areas. Proximity, reputation and prior networks were prioritized when forming $\mathrm{H} 3$, even though both alternative scenarios would probably have required less process realignment. Other examples of shared service centres, however, indicate that more "exotic" partnerships are possible. And even for joint provision of frontline public services, partner selection could be more flexible than for traditional complexity-driven collaboration, subject to the limited mobility of physical assets. Whether that potential is fulfilled, or whether other considerations such as partner familiarity, cultural similarity and trustworthiness have a greater impact, remains an empirical question.

Secondly, there is the institutional collective action problem, which describes why actors often fail to collaborate when doing so would achieve a common objective (Feiock, 2013). Perceived costs and benefits matter in this context, and could operate dissimilarly for complexity- and efficiency-driven, although the consequences of this are not yet clear. Task interdependencies can be positive or negative in direction, either building on synergies or managing negative externalities (Huxham \& MacDonald, 1992); whereas scale interdependencies appear to be inherently positive, concerned with mutually-beneficial up-scaling. So the incentive to collaborate is somewhat different for the complexity and efficiency types, although not obviously stronger or weaker. Additionally, if significant task interdependencies result from addressing scale interdependence (as with $\mathrm{H} 3$ ), and if these task connections are more obvious and easily recognized, this downside to efficiency-driven collaboration may figure more prominently in decision-making, leading to reluctance to collaborate. 
This might explain the pessimistic attitudes and actor resistance towards collaborative efficiency measures often reported in the literature (Boon \& Verhoest, 2017).

Thirdly, in terms of partnership sustainability, the impact of partner disengagement will manifest differently for task- and scale-inspired collaborations, which might affect "exit" decisions. With the former, failure to collaborate will reduce the quality of policymaking and public services where a multiagency "joinedup" approach is required, deteriorating the citizen experience. With the latter, disengagement will leave a hole in the agency budget if services cost more when delivered autonomously. This will place additional demand on organizational revenues, which may or may not be perceived by external stakeholders.

Turning to partnership operations, two areas for research emerge. Regarding practical management challenges, it seems unlikely that there are intrinsic operational differences between complexity and efficiency collaborations. Although driven by scale interdependencies, the $\mathrm{H} 3$ project required significant alterations to internal processes in member organizations. Many ex-post task interdependencies emerged and needed managing - which, of course, is the raison d'être of complexitydriven collaboration. So collaborative management may be similar no matter what the triggering interdependency. Nonetheless, in terms of the "integrative leadership" required to inspire separate actors to coordinate and compromise (Crosby \& Bryson, 2010), there could be distinct challenges. Principally, task interdependencies often involve a compelling social mandate focused on resolving pressing "wicked issues" at the frontline. Efficiency gains may seem mundane or low priority by comparison, leading to reduced interest and prioritization among staff.

Finally, regarding partnership outcomes, there may be differences in goal specificity, goal congruence and performance measurability when resolving task and 
scale interdependencies, with a number of important consequences. Demonstration of good performance improves collaborative legitimacy and encourages participation, whereas a negative evaluation risks dissention and defection. Difficulty in measuring performance also increases transaction costs and thus lowers the propensity to collaborate. On the one hand, mainstream task-complexity collaboration often suffers from "multiple and competing stakeholder perceptions of how to define results and outcomes," making evaluation difficult (Bryson et al.2015, p. 357). By contrast, if cost-reduction is the primary aim of efficiency-driven collaboration, goal specificity, goal congruence and performance evaluation might all be improved, reaping the advantages to legitimacy, participation and transaction costs described above. On the other hand, partners may still disagree about how to divide investments and savings; and, if the goal is efficiency, not simply economy, then service quality should still be measured, which could be conceived differently by different parties. Again, empirical work is needed to explore these issues.

\section{Conclusions}

Productive efficiency is an important but under-researched motive for collaboration in the public sector. Despite growing interest from policymakers and academics in what we have termed "collaborative efficiency measures," there is uncertainty about how this type of collaboration compares to the more familiar task-complexity form, and whether this distinction results in significant differences in partnership formation, operation and outcomes. Consequently, this article has used a multi-dimensional conceptualization of interdependence, derived from organization theory, to relate the complexity and efficiency forms of collaboration and develop a framework for future research. This perspective indicates that interdependencies are both a cause and a consequence of inter-organizational collaboration, that variation in their strength, 
intricacy, direction and recognition condition how the partnership unfolds, and that different governance arrangements are used to handle these interdependencies. We illustrated these concepts and some of their interconnections with a recent example from England, and then considered some of the most promising research questions which might in future draw on the analytic framework to compare complexity- and efficiency-driven collaboration.

Organization theory provides a nuanced and multidimensional framework for analysing inter-organizational relations in the public sector, beyond what is currently available in both economics and public management. Although there is some overlap with existing theories, for instance in terms of defection, opportunism and negative interdependence, use of these alone would provide only partial view of the unfolding of our H3 example - and, crucially, would not distinguish between and relate the complexity and efficiency motives for the collaboration. Nonetheless, the framework is not without its limitations. One is the difficulty of operationalizing some concepts, such as strength and intricacy, in large- $\mathrm{N}$ research. Yet quantitative organization studies demonstrate that this is achievable, and provides some fruitful lessons (see Price, 1972). Another is that the model is primarily functionalist, explaining decisions in rational and instrumental terms, and ignoring the politics of collaboration. We partly address this by including the "recognition" variable, which allows for social construction and imperfect information about interdependencies. We also borrow several rational-choice concepts to accommodate self-interest and bargaining. Future research could go further in this direction. Transaction cost economics theorizes the "friction" arising in exchange relationships due to individual interests and bounded rationality (Carr \& Hawkins, 2013; Feiock, 2013), and would provide a 
fruitful complement. Sociological approaches to group interaction and compromise would also be informative (Banoun et al., 2016).

Empirically, of course, many other possibilities for fruitful development of the literature on collaborative cost cutting. Given the prevalence of decentralized forms of public service delivery around the world, and the challenging fiscal environment, it seems unlikely that collaborative efficiency measures will disappear from the reform agenda anytime soon - whether in central or local government. Priority questions include: how do internal and collaborative approaches to cost cutting compare in terms of results? Can they complement one another, or are there trade-offs - for instance, if internal reforms require de-regulation and managerial discretion while collaboration brings standardization and loss of autonomy? To what extent do expost interdependencies dampen the achievements of collaborative cost-cutting reforms? How can this be measured empirically, and how might public managers make decisions to ensure a net benefit to collaboration? Finally, what is the nonfinancial impact of reform - say, on political and bureaucratic accountability or responsiveness to citizen preferences? These are all important questions in need of attention. They can be better tackled once ambiguity about the status of efficiencydriven collaboration vis-à-vis the familiar complexity type is reduced. 


\section{Bibliography}

Accenture. (2005). Driving High Performance in Government: Maximising the Value of Public-Sector Shared Services. London: Accenture.

Aiken, M., \& Hage, J. (1968). Organizational Interdependence and Intra-Organizational Structure. American Sociological Review, 33(6), 912-930.

Alexander, E. R. (1995). How Organizations Act Together: Interorganizational Coordination in Theory and Practice. Luxembourg: Gordon and Breach.

Allers, M. A., \& de Greef, J. A. (forthcoming). Intermunicipal cooperation, public spending and service levels. Local Government Studies.

Andrews, R., \& Entwistle, T. (2013). Public Service Efficiency: Reframing the Debate. Abingdon, Oxon: Routledge.

Baldwin, D. A. (1980). Interdependence and power: a conceptual analysis. International Organization, 34(4), 471-506.

Banoun, A., Dufour, L., \& Andiappan, M. (2016). Evolution of a service ecosystem: Longitudinal evidence from multiple shared services centers based on the economies of worth framework. Journal of Business Research, 69(8), 2990-2998.

Bel, G., Fageda, X., \& Mur, M. (2014). Does Cooperation Reduce Service Delivery Costs? Evidence from Residential Solid Waste Services. Journal of Public Administration Research and Theory, 24(1), 85-107.

Bel, G., \& Warner, M. E. (2015). Inter-municipal cooperation and costs: expectations and evidence. Public Administration, 93(1), 52-67.

Besanko, D., Dranove, D., Shanley, M., \& Schaefer, S. (2003). Economics of Strategy: Wiley.

Blåka, S. (forthcoming). Does Cooperation Affect Service Delivery Costs? Evidence from Fire Services in Norway. Public Administration.

Boon, J., \& Verhoest, K. (2017). On the Dynamics of Reform Resistance: Why and How Bureaucratic Organizations Resist Shared Service Center Reforms. International Public Management Journal, 125.

Bouckaert, G., Peters, B. G., \& Verhoest, K. (2010). The Coordination of Public Sector Organizations: Shifting Patterns of Public Management. Basingstoke: Palgrave Macmillan.

Bovaird, T. (2014). Efficiency in Third Sector Partnerships for Delivering Local Government Services: The role of economies of scale, scope and learning. Public Management Review, 16(8), 1067-1090.

Bryson, J. M., Crosby, B. C., \& Stone, M. M. (2015). Designing and Implementing Cross-Sector Collaborations: Needed and Challenging. Public Administration Review, 75(5), 647-663.

Cabinet Office. (2012). Next Generation Shared Services: The Strategic Plan. London: Cabinet Office.

Carr, J. B., \& Hawkins, C. V. (2013). The costs of cooperation: what the research tells us about managing the risks of service collaborations in the U.S. State \& Local Government Review, 45(4), 224-239.

Challis, L., Fuller, S., Henwood, M., Klein, R., Plowden, W., Webb, A., . . Gerald, W. (1988). Joint Approaches to Social Policy. Cambridge: Cambridge University Press. 
Chen, Y.-C., \& Thurmaier, K. (2008). Interlocal Agreements as Collaborations. The American Review of Public Administration, 39(5), 536-552.

Chisholm, D. (1989). Coordination Without Hierarchy: Informal Structures in Multiorganizational Systems. Berkeley: University of California Press.

Crosby, B. C., \& Bryson, J. M. (2010). Integrative leadership and the creation and maintenance of cross-sector collaborations. The Leadership Quarterly, 21(2), 211-230.

Department for Communities and Local Government. (2012). 50 Ways to Save: Examples of Sensible Savings in Local Government. London: The Stationery Office.

Department of Finance. (2015). Whole-of-Government Shared and Common Services Programme. Canberra: Canberra.

Department of Public Expenditure and Reform. (2011). Public Service Reform. Dublin: DPER.

Deutsch, M. (1949). A Theory of Co-operation and Competition. Human Relations, 2(2), 129-152.

Dollery, B., Grant, B., \& Kortt, M. (2012). Councils in Cooperation: Shared Services and Australian Local Government. Annandale: Federation Press.

Elston, T., \& Dixon, R. (2017). The Effect of Shared Service Centres on Administrative Intensity in English Local Government: A Longitudinal Evaluation. Blavatnik School of Government Working Paper, BSG-WP-2017/021. Oxford University.

Elston, T., \& MacCarthaigh, M. (2016). Sharing services, saving money? Five risks to cost saving when organizations share services. Public Money \& Management, 36(5), 349-356.

Feiock, R. C. (2013). The Institutional Collective Action Framework. Policy Studies Journal, 41(3), $397-425$.

Gershon, P. (2004). Releasing Resources to the Front Line: Independent Review of Public Sector Efficiency. London: The Stationery Office.

Gray, B. (1985). Conditions Facilitating Interorganizational Collaboration. Human Relations, 38(10), 911-936.

Gulati, R., \& Gargiulo, M. (1999). Where do interorganizational networks come from? American Journal of Sociology, 104(5), 1439-1493.

Hale, T., Held, D., \& Young, K. (2013). Gridlock: From Self-reinforcing Interdependence to Secondorder Cooperation Problems. Global Policy, 4(3), 223-235.

Hastings, A., Bailey, N., Gannon, M., Besemer, K., \& Bramley, G. (2015). Coping with the Cuts? The Management of the Worst Financial Settlement in Living Memory. Local Government Studies, 41(4), 601-621.

Hood, C. (1976). The Limits of Administration. London: Wiley.

Hood, C., Huby, M., \& Dunsire, A. (1985). Scale economies and iron laws: Mergers and demergers in Whitehall 1971-1984. Public Administration, 63(1), 61-78.

Huxham, C., \& MacDonald, D. (1992). Introducing Collaborative Advantage: Achieving Interorganizational Effectiveness Through Meta-Strategy. Management Decision, 30(3), 50.

Keast, R., Brown, K., \& Mandell, M. (2007). Getting The Right Mix: Unpacking Integration Meanings and Strategies. International Public Management Journal, 10(1), 9-33. 
Litwak, E., \& Rothman, J. (1970). Towards the theory and practice of coordination between formal organizations. In W. R. Rosengren \& M. Lefton (Eds.), Organizations and Clients: Essays in the Sociology of Service (pp. 137-186). Columbus, Ohio: Charles E. Merrill.

March, J. G., \& Simon, H. A. (1993). Organizations (2nd ed.). Cambridge, Mass.,: Blackwell.

Mintzberg, H. (1979). The Structuring of Organizations. Englewood Cliffs, New Jersey: Prentice Hall.

National Audit Office. (2016). Shared Service Centres. (HC 16, Session 2016-17). London: The Stationery Office.

Niaounakis, T., \& Blank, J. (2017). Inter-Municipal Cooperation, Economies of Scale and Cost Efficiency: An Application of Stochastic Frontier Analysis to Dutch Municipal Tax Departments. Local Government Studies, 43(4), 533-554.

Oakerson, R. (1992). Size, function, and structure: jurisdictional size effects on public sector performance. Paper presented at the Proceedings of the Annual Meeting of the National Rural Studies COmmittee, Las Vegas, New Mexico.

Office of Management and Budget. (2016). Improving Administrative Functions through Shared Services. (M-16-11). Memorandum for the Heads of Executive Departments and Agencies.

Oliver, C. (1990). Determinants of Interorganizational Relationships: Integration and Future Directions. Academy of Management Review, 15(2), 241-265.

Ostrom, V. (1974). The Intellectual Crisis in American Public Administration. Tuscaloosa, Alabama: University of Alabama Press.

Ostrom, V., Tiebout, C. M., \& Warren, R. (1961). The Organization of Government in Metropolitan Areas: A Theoretical Inquiry. American Political Science Review, 55(04), 831-842.

Paagman, A., Tate, M., Furtmueller, E., \& de Bloom, J. (2015). An integrative literature review and empirical validation of motives for introducing shared services in government organizations. International Journal of Information Management, 35(1), 110-123.

Partnership for Public Service, \& Deloitte. (2015). Building a Shared Services Marketplace Washington DC.

Peters, B. G. (2015). Pursuing Horizontal Management: The Politics of Public Sector Coordination. Lawrence, KS: University Press of Kansas.

Pfeffer, J., \& Salancik, G. R. (1978). The External Control of Organizations: A Resource Dependence Perspective. New York: Harper \& Row.

Pollitt, C., \& Bouckaert, G. (2011). Public Management Reform: A Comparative Analysis: New Public Management, Governance, and the Neo-Weberian State. Oxford: Oxford University Press.

Price, J. L. (1972). Handbook of Organizational Measurement. Lexington, Mass.

Raudla, R., \& Tavares, A. F. (2018). Intermunicipal cooperation and austerity policies: obstacles or opportunities? In F. Teles \& P. Swianiewicz (Eds.), Inter-Municipal Cooperation in Europe: Institutions and Governance (pp. 17-40). Basingstoke: Palgrave Macmillan.

Silva, C. (2017). Picking the team: a preliminary experimental study of the activation of collaborative network members. Journal of Public Administration Research \& Theory.

Simon, H. A. (1997). Administrative Behavior. New York: Free Press. 
Thompson, G., Frances, J., Levačić, R., Mitchell, \& Jeremy. (1991). Markets, Hierarchies \& Networks: The Coordination of Social Life. London: Sage.

Thompson, J. D. (1967). Organizations in Action: Social Science Bases of Administrative Theory. New York: McGraw-Hill.

Thurmaier, K., \& Wood, C. (2004). Interlocal agreements as an alternative to consolidation. In J. B. Carr \& R. C. Feiock (Eds.), City-County Consolidation and Its Alternatives: Reshaping the Local Government Landscape. New York: Routledge.

Tjosvold, D. (1986). The Dynamics of Interdependence in Organizations. Human Relations, 39(6), $517-540$

Tomkinson, R. (2007). Shared Services in Local Government: Improving Service Delivery. Aldershot: Gower.

Verhoest, K., Van Thiel, S., Bouckaert, G., \& Lægreid, P. (Eds.). (2011). Government Agencies: Practices and Lessons from 30 Countries. Basingstoke: Palgrave Macmillan.

Walker, H., Schotanus, F., Bakker, E., \& Harland, C. (2013). Collaborative Procurement: A Relational View of Buyer-Buyer Relationships. Public Administration Review, 73(4), 588-598.

Zafra-Gómez, J. L., Prior, D., Díaz, A. M. P., \& López-Hernández, A. M. (2013). Reducing costs in times of crisis: Delivery forms in small and medium sized local governments' waste management services. Public Administration, 91(1), 51-68.

Zeemering, E. (forthcoming). Why Terminate? Exploring the End of Interlocal Contracts for Police Service in California Cities. The American Review of Public Administration. 
Figure 1. Conceptual framework

\section{Ex-ante interdependence}

TASK

(mainstream collaborative public management)

- How strong?

- How intricate/predictable?

- What direction?

- Who recognizes?

(outcomes contingent on group behaviour)

$$
\text { L }
$$

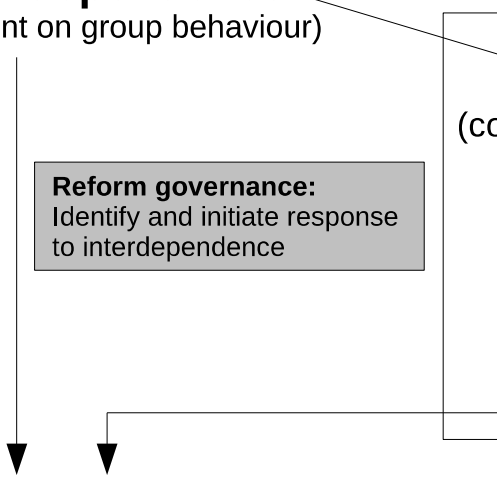

SCALE

(collaborative efficiency measures)

- How strong?

- How intricate/predictable?

- What direction?

- Who recognizes?
Feedback loop from ex-post interdependence into operational governance

\section{Ex-post interdependence}

(collaboration results in reduced autonomy and increased bargaining to make decisions)

- What type? (Task, scale, other?)

- How strong?

- How intricate/predictable?

- What direction?

- Who recognizes? 